\title{
Integração curricular na formação superior em saúde: refletindo sobre o processo de mudança nos cursos do Unifeso
}

\section{Curricular integration in the education of health professionals: reflections about the process of changes in Unifeso's graduation courses}

- Educação;

- Saúde;

- Currículo;

- Prática Profissional.

KEY-WORDS:

- Education;

- Health;

- Curriculum;

- Professional Practice.

Recebido em: 15/09/2007

Aprovado em: 13/02/2007

\author{
Verônica Santos Albuquerque ${ }^{1}$ \\ Suzelaine Tanji ${ }^{1}$ \\ Carmen Maria dos Santos Lopes Monteiro Dantas da Silva ${ }^{1}$ \\ Edneia Tayt-Sohn Martuchelli Moço ${ }^{1}$ \\ Kátia Cristina Felippe ${ }^{1}$ \\ José Feres Abido Miranda ${ }^{1}$
}

\section{R E S U M}

Este artigo discute a integração de currículos para formação profissional em saúde a partir de um relato de experiência. Trata-se do movimento de mudança curricular dos Cursos de Medicina, Enfermagem e Odontologia do Centro Universitário Serra dos Órgãos (Unifeso), Teresópolis RJ. Apresenta-se a construção de eixos transversais para os três cursos a partir de uma oficina de imersão, realizada na instituição no primeiro semestre de 2007. Como produto desse encontro, surgiu uma proposta de quatro eixos transversais em comum, compondo as dimensões curriculares dos cursos: Semiologia Ampliada do Sujeito e da Coletividade; Ética e Humanismo; Construção e Produção do Conhecimento; e Política e Gestão em Saúde. Esses eixos perpassam toda a formação dos profissionais de saúde e se articulam. Tal proposta vem ganhando vida no exercício prático do cotidiano dos currículos na instituição. Com a divulgação desta experiência pretendese apresentar a possibilidade de uma formação integrada entre as diferentes profissões da saúde como um fator potencializador do trabalho em equipe.

\section{A B S T R A C T}

The aim of this article is to discuss curricular integration in the education of health professionals on the basis of an experience, the Movement for Curricular Changes in the Medicine, Nursing and Dentistry Courses of the Centro Universitário Serra dos Órgãos (UNIFESO), Teresópolis RJ. This text presents the process of constructing transversal axes between the three mentioned courses. In the first semester of 2007 an immersion workshop was held in the institution for identifying common subject matters. The workshop resulted in a proposal of four transverse axes composing the curricular dimensions of the three courses: Individual and Collective Semiology; Ethics and Humanism; Knowledge Construction and Production; and Health Policies and Management. Those axes are interlinked and crosscut the entire education of these health professionals. In fact, this proposal is put in practice in the institution's every-day curricular routine. By disclosing this experience we intend to promote the possibility of an integrated curriculum for the different health professions as a potentializer of teamwork. 


\section{CONSIDERAÇÕES INICIAIS}

O Centro de Ciências da Saúde (CCS) do Centro Universitário Serra dos Órgãos (Unifeso) é uma instância acadêmica e administrativa, à qual estão vinculados os cursos de graduação em Medicina, Odontologia, Enfermagem, Fisioterapia e Medicina Veterinária. Dentre esses, os Cursos de Medicina, Enfermagem e Odontologia, há alguns anos, vêm reunindo esforços na discussão e reflexão sobre a mudança curricular.

A proposta de mudança inclui a formação para o fortalecimento do modelo de atenção à saúde no qual o compromisso fundamental é com as necessidades do usuário ("usuário-centrado"), como contrapartida do modelo atualmente predominante, em que o principal compromisso do ato de assistir à saúde é com a produção de procedimentos ("procedimento-centrado"). Para isto, o perfil esperado do profissional de saúde compreende o compromisso com a universalidade, a eqüidade e a integralidade do cuidado. A idéia é que a formação deve permitir o entendimento da necessidade de garantia do cuidado que as pessoas demandam, em todas as suas dimensões, das atividades de promoção e prevenção até aquelas que envolvem serviços com maior densidade tecnológica. Enfim, o que se deseja é uma formação que garanta o equilíbrio entre a excelência técnica e a relevância social.

Em 2005, o curso de Medicina iniciou seu processo de mudança com o apoio dos ministérios da Educação e da Saúde, assim como da Organização Pan-Americana de Saúde, por intermédio do Programa de Incentivo às Mudanças Curriculares nos Cursos de Medicina (Promed), (re)significado na instituição como Projeto EducAção. Esse projeto delineou perfis e propostas de ação dentro de uma concepção de modelo de formação e de atenção à saúde em que os estudantes, os docentes e a sociedade são sujeitos ativos no processo ensinoaprendizagem, num contexto de integração entre ensino, trabalho e cidadania.

Entendendo a necessidade de ampliar o movimento de mudança para outros cursos da saúde e com o objetivo de integrar as ações, o Ministério da Saúde, por intermédio da Secretaria de Gestão do Trabalho e da Educação na Saúde (SGTES), em conjunto com a Secretaria de Educação Superior do Ministério da Educação (Sesu/MEC), conduziu o processo de elaboração do Programa Nacional de Reorientação da Formação Profissional em Saúde (Pró-Saúde). A Unifeso teve seu projeto novamente aprovado, naquele momento, para os cursos de Medicina, Enfermagem e Odontologia.

Assim, no primeiro semestre de 2007, os cursos de Enfermagem e Odontologia iniciaram a operacionalização da mudança curricular com transformações efetivas no primeiro período, enquanto o curso de Medicina avançava para o quarto período do novo currículo.

Nos três cursos, a mudança curricular foi marcada pela implantação do currículo integrado. O princípio é o do currículo em espiral, que propõe a organização do curso partindo do geral para o específico, em níveis crescentes de complexidade e sucessivas aproximações com a realidade abstrata e concreta ${ }^{1}$. Esse princípio sustenta a construção de seqüências de conhecimentos definidos a partir das competências a serem alcançadas. Assim, novos conhecimentos e habilidades (cognitivas, afetivas e psicomotoras) são introduzidos em momentos subseqüentes, retomando o que já se sabe e mantendo as interligações com as informações previamente aprendidas. Com isso, pretende-se que o estudante alcance, gradualmente, maior amplitude e profundidade do conhecimento $^{2}$. O currículo integrado contempla conhecimentos, habilidades e atitudes nos quatro domínios propostos por Delors ${ }^{3}$ - o saber conhecer, o saber fazer, o saber ser e o saber conviver -, compreendendo que essas vias do saber constituem apenas uma, ou seja, existem entre elas múltiplos pontos de contato, de relacionamento e de permuta.

Considerando esses pressupostos, as grades curriculares, baseadas em disciplinas, foram substituídas por um modelo integrado de atividades curriculares, composto por módulos (tutorial e de prática profissional). A pedagogia da transmissão, amplamente utilizada no formato curricular anterior, foi substituída por metodologias ativas de aprendizagem, e, nesse novo contexto, os estudantes passaram a imergir no mundo do trabalho desde o primeiro período.

Diante da contemplação do Pró-Saúde e das mudanças curriculares efetivadas nos cursos do Centro de Ciências da Saúde do Unifeso, surgiu uma nova expectativa e uma inquietação, relacionada à questão de como estreitar e fortalecer a integração entre os três cursos, considerando a necessidade de repensar o currículo a partir dos princípios da interligação dos saberes, da formação para o trabalho em equipe e da construção de competência coletiva.

As propostas de formação e de exercício do trabalho interdisciplinar já estão colocadas como realidade em nossa sociedade para a área da saúde, não cabendo legitimidade a qualquer apelo em contrário. Prova disso é a constância da designação do trabalho em equipe em qualquer circunstância propositiva de elevação da qualidade do trabalho e da formação em saúde. A orientação do trabalho em equipe consta tanto das diretrizes para a formação dos profissionais da saúde, quanto das diretrizes para o exercício profissional no Sistema Único de Saúde (SUS) ${ }^{4}$. 
Para dar seguimento ao processo de mudança nos três cursos, que implantaram o currículo integrado, foi instituída uma comissão, denominada Grupo Gestor, composta por docentes vinculados à gestão institucional e aos cursos de graduação envolvidos. Além do Grupo Gestor, foi implantado o Comitê Local de Acompanhamento do Pró-Saúde, que envolve representações da gestão municipal de saúde e do Unifeso, dos docentes, dos discentes, dos profissionais de saúde da rede local e membros do Conselho Municipal de Saúde. Tal comitê objetiva democratizar as relações entre universidade, serviços de saúde e comunidade, além de promover o acompanhamento do processo de mudança curricular e nos serviços de saúde, visando considerar as diretrizes e princípios do SUS.

No primeiro semestre de 2007, o Grupo Gestor e o Comitê Local de Acompanhamento, mobilizados pelas mudanças no cenário acadêmico e com o objetivo de ampliar as discussões sobre as dimensões curriculares dos cursos, propôs uma oficina de imersão para (re)planejar estratégias de integração. Foram envolvidos docentes e gestores dos cursos de Medicina, Enfermagem e Odontologia, além de profissionais e gestores dos serviços de saúde. O produto final esperado era uma proposta de condução do processo de mudança alicerçada na interdisciplinaridade e na integração curricular desses cursos.

Para tanto, o presente trabalho, a título de um relato de experiências, tem como propósito descrever as reflexões, debates e discussões que emergiram do encontro/oficina de imersão, relacionados com a integração dos projetos pedagógicos dos cursos de graduação em Enfermagem, Medicina e Odontologia do Unifeso.

\section{DESCREVENDO A TRAJETÓRIA}

As discussões/reflexões do encontro/oficina de imersão foram relacionadas às indagações mais prementes dos sujeitos envolvidos, estruturadas a partir de três questões norteadoras: "o currículo que temos", "o currículo que queremos" e "como chegar lá".

Foram constituídos três grupos de trabalho, divididos de maneira integradora, compostos, cada um, por 12 a 13 pessoas, de modo que nestes houvesse a representatividade dos cursos de Medicina, Enfermagem e Odontologia e, ainda, de outros atores que atuam em diferentes cenários dos serviços de saúde do município.

Após exaustivas e produtivas discussões sobre os projetos pedagógicos dos cursos e seus problemas de funcionalidade, emergiu o produto, fruto de reflexões que perpassaram subjetividades, compreensões polissêmicas bastante desejáveis e pistas para reorganização dos processos de formação institucionais e das práticas de saúde locais.
O produto se apresenta como o diagnóstico das vulnerabilidades na integração das dimensões curriculares dos três cursos e a proposta de integração a partir de quatro eixos transversais, apresentados no item que se segue.

\section{APRESENTANDO O RESULTADO: O PRODUTO}

Para se alcançar o propósito da integração, chegou-se ao consenso de que seria fundamental e oportuno refletir sobre as dimensões curriculares dos cursos. Tal reflexão foi permeada pela concepção de interdisciplinaridade.

A discussão da interdisciplinaridade no campo de formação em saúde exige um referencial mais próximo à idéia de atitude: atitude de buscar alternativas para conhecer mais e melhor; atitude de reciprocidade que impele à troca, ao diálogo com pares idênticos, com pares distintos ou consigo mesmo; atitude de humildade diante da limitação do próprio saber; atitude de perplexidade ante a possibilidade de desvelar novos saberes; atitude de desafio diante do novo; atitude de responsabilidade, envolvimento e comprometimento com os projetos e as pessoas ${ }^{5}$.

\section{O currículo que temos}

No decorrer das reflexões propostas na oficina, percebeuse que os três cursos organizaram seus currículos em eixos ou áreas de competências, que, embora se mostrassem sobrepostas ou imbricadas, passavam a descaracterizar um modelo de mudança institucionalmente integrado.

O curso de Medicina, desde 2005, baseou seu processo de mudança em três eixos: Semiologia Ampliada do Sujeito; Ética e Humanismo; e Instrumentalização para Pesquisa. O curso de Enfermagem construiu seu currículo com base em três áreas de competência: Cuidado à Saúde; Político-Gerencial; e Educação e Pesquisa. Já o curso de Odontologia assumiu quatro eixos: Ato de Estudar; Processo Saúde-Doença; Módulo de Prática Profissional; e Organização dos Serviços de Saúde.

\section{O currículo que queremos}

Considerando as dimensões da organização de cada curso e visando a um olhar mais ampliado e articulado do processo, forma-se como proposta a integração dos três cursos, a partir de eixos que passam a ser comuns a todos:

- Semiologia ampliada do sujeito e da coletividade;

- Ética e humanismo;

- Construção e produção do conhecimento;

- Política e gestão em saúde. 
Cada eixo foi constituído de forma a garantir consonância com os princípios e diretrizes expostos no Projeto Político Pedagógico Institucional (PPPI) do Unifeso.

\section{O eixo Semiologia Ampliada do Sujeito e da Coletividade}

Este eixo se baseia na concepção de Semiologia Ampliada do Sujeito, na qual a Semiologia é entendida não apenas como técnica de diagnóstico e de observação de sinais e sintomas das doenças, mas assume um sentido amplo, que incorpora essa dimensão à ciência geral de todos os signos: "a vida dos signos no seio da vida social" ${ }^{\prime \prime}$, ou seja, a técnica vista, principalmente, como cuidado.

A denominação Semiologia Ampliada do Sujeito e da Coletividade se baseou nos seguintes pressupostos:

- A construção do novo - valorizando a cultura, as relações de trabalho, a política, os valores da comunidade e o perfil epidemiológico da população envolvida. Na verdade, a construção de um novo paradigma: o sujeito que necessita de atenção em saúde e deve ser considerado em seus aspectos pessoais, biológicos, sociais, culturais, ambientais e econômicos;

- Os processos de construção de autonomia dos sujeitos, que têm como fundamento o próprio modelo pedagógico a ser adotado;

- O deslocamento da ênfase na doença, centrando a atenção no sujeito social. A doença deixa de ser o objeto de atenção, e a centralidade do cuidado se desloca para o sujeito que adoece/pode adoecer. Desse modo, o olhar técnico sobre a doença é considerado em função da pessoa e das coletividades;

- A base para a proposição de estratégias de construção é a transformação da atenção aos sujeitos e às coletividades nos campos teórico, educacional, assistencial e político-gerencial do SUS. As estratégias contemplam desde arranjos conceituais para facilitar a incorporação de saberes de diversos campos até a discussão e proposição de algumas ferramentas de gestão em saúde;

- Os cenários de ensino-aprendizagem devem ser ampliados e diversificados em todos os níveis de atenção à saúde, considerando as concepções de cuidado e de integralidade.

No Projeto Político Pedagógico Institucional (PPPI, 2006) do Unifeso, há princípios filosóficos educacionais coerentes com o eixo Semiologia Ampliada do Sujeito e da Coletividade, o que percebemos na assertiva que se segue: "a educação é um processo de formação integral, integrada, integrante e integradora das pessoas e dos grupos. Ela se faz na liberdade do ser humano. Nisso reside o fundamento da autonomia moral e intelectual, que é uma capacidade a ser exercida pelos atores do processo educacional, e seu desenvolvimento se dá em função de uma prática educativa coerente com esta finalidade"7. Portanto, consideramos essencial considerar como atores/sujeitos envolvidos no processo de aprender a aprender todos aqueles que se inserem na realidade, seja do ensino, do serviço de saúde e/ou da comunidade.

Por fim, este eixo traz reflexões sobre a abrangência do trabalho em saúde, cujo objeto indica a responsabilidade sanitária além da doença e a incorporação de conceitos - como problema de saúde, produção social de saúde e vulnerabilidade - sempre encarnados em sujeitos, indivíduos, famílias e coletivos. Tais questões se inserem numa seara epistemológica, na qual o sujeito pertence a contextos, enquanto ator social ${ }^{8}$.

A Semiologia Ampliada do Sujeito e das Coletividades começa, então, a perpassar toda a formação proposta pelos cursos de Medicina, Enfermagem e Odontologia, articulandose com os outros eixos gerais: Ética e Humanismo; Construção e Produção do Conhecimento; e Políticas e Gestão em Saúde.

\section{O eixo Ética e Humanismo}

Nossa proposta de humanização do ensino em saúde parte do princípio de que é preciso desenvolver nos estudantes, nos professores, nos serviços e nas comunidades os valores essenciais à formação da cidadania, possibilitando uma visão integral do processo saúde-doença a partir de seus determinantes físicos, biológicos, psicológicos, socioeconômicos, ambientais, culturais e políticos.

Na problematização da realidade, desenvolvemos nossa reflexão sobre ética como um ato de mediação que valorize seus dois sentidos - o individual e o coletivo. O primeiro é referente ao indivíduo, seus hábitos, comportamentos, características e significado existencial; o segundo diz respeito ao ethos social, nossos hábitos, tradições, nosso modo de viver em conjunto. Essa dualidade é potencialmente conflitante e até mesmo contraditória9 ${ }^{9}$

Considerar o conceito de ética como o estudo do comportamento moral dos seres humanos em sociedade compreende o conjunto de normas de comportamento e formas de vida por meio dos quais os seres humanos tendem a realizar o valor do bem. Inspira a coerência entre os fins e os meios utilizados para alcançá-los, no propósito de defender valores fundamentais, como a vida, a dignidade humana e o 
respeito entre os homens. É também a capacidade humana de pensar as próprias finalidades de seu agir social.

Nesse sentido, a proposta é que os currículos contemplem a ética e o humanismo em todas as atividades de ensinoaprendizagem. Os princípios de ética e bioética também são considerados na sensibilização dos docentes dos três cursos, visando a um trabalho sistêmico com ênfase na formação humanística.

Este eixo é concebido de forma interdisciplinar, envolvendo diversas áreas de formação afins. Um ponto de grande importância é voltá-lo também para a reestruturação/ humanização dos diversos cenários de ensino-aprendizagem. Convém salientar que o trabalho com este eixo terá como princípio a problematização da realidade. Para que isso se efetive, diferentes áreas do conhecimento serão envolvidas, visando, também, à intersetorialidade.

Desse modo, acreditamos que teremos condições de valorizar o uso da técnica contextualizada em seu sentido filosófico/conceitual, como uma dimensão do cuidado. Assim, é possível relacionar o uso das tecnologias duras ${ }^{10}$ (quando necessária a sua utilização) como meio de diagnóstico e tratamento, e não como um fim em si mesmo.

A ética, a bioética e o humanismo propiciam ao estudante uma visão sistêmica da sua formação. Por ser um eixo fundamental, perpassa toda a construção da identidade profissional.

\section{Eixo Construção e Produção do Conhecimento}

Este eixo está em correlação dinâmica e contínua com os demais, uma vez que a construção/ produção do conhecimento ocorre em todos os cenários e situações vivenciados pelos atores no processo ensino-aprendizagem, com o objetivo de fornecer respostas, propor instrumentos e meios, bem como construir métodos de intervenção capazes de atender às demandas dos serviços em que os estudantes estão inseridos.

Tal eixo pressupõe a interdisciplinaridade, a diversificação de cenários e metodologias de aprendizagem centradas nos estudantes, com vistas ao desenvolvimento de autonomia e à incorporação da idéia de educação permanente como uma prática contínua durante a formação (incluindo a vida profissional após a graduação).

A proposta é desenvolver o aprender a conhecer, defendido por Delors33, que é indissociável do aprender a fazer. $\mathrm{Na}$ constituição deste eixo, considera-se o horizonte formativo como um processo por meio do qual a aprendizagem se torna dinâmica constitutiva pela vida afora. A formação é entendida, então, como processo. Não começa nem acaba, está sempre em andamento. É uma dinâmica profunda, que vai além do manejo de informação ${ }^{11}$.

O eixo foi construído a partir das seguintes diretrizes gerais:

- Remeter o objetivo geral da construção do conhecimento às necessidades de saúde da população, evitando abordagens reducionistas ou utilitaristas;

- Produzir conhecimento pautado nos padrões éticos;

- Sustentar a integração teoria-prática como um exercício de lógicas complementares;

- Aumentar a capacidade investigativa a partir da integração graduação/pós-graduação e das diretrizes gerais das políticas de saúde e educação.

A finalidade de incorporar este eixo do primeiro ao último ano de formação é potencializar o leque da investigação que tenha como finalidade, imediata ou mediata, contribuir para a melhoria do estado de saúde da população e para a redução das desigualdades sociais no cuidado à saúde.

Deste modo, reafirma-se o conceito institucional de que a construção e a produção do conhecimento deverão promover “a formação do cidadão participativo e do profissional reflexivo, que não apenas se utiliza do conhecimento e da técnica, mas recria e atualiza novas formas de domínio, apropriação e aplicação do saber científico para o bem-estar da sociedade"7.

\section{Eixo Política e Gestão em Saúde}

A política e a gestão em saúde integram o campo de ação social, orientando para a melhoria das condições de saúde da população e dos ambientes natural, social e do trabalho. Sua tarefa específica em relação às outras políticas públicas da área social consiste em organizar as funções públicas governamentais para a promoção, proteção e recuperação da saúde individual e coletiva.

A gestão social das políticas públicas de saúde tem como uma de suas bases a formação de atores que afirmam a saúde como direito de cidadania, explícito na Carta Constitucional.

A política de formação para a gestão pública compreende a educação em saúde que se realiza nos serviços, no encontro entre estudantes, profissionais e usuários. $\mathrm{O}$ sentido das ações volta-se para a promoção do bem viver e para o encontro de saberes e práticas de saúde inseridos no cotidiano das relações sociais.

Uma das maneiras de abordar questões relacionadas à gestão em saúde pode ser amparada nos princípios da educação permanente. Essa estratégia promove a condição indispensável para uma pessoa ou organização decidir mudar ou incorporar novos elementos à sua prática e a seus conceitos, 
que é o desconforto, a percepção de que a maneira vigente de fazer ou de pensar é insuficiente ou insatisfatória para dar conta dos desafios do trabalho.

Na concepção da gestão em saúde, a educação permanente é uma estratégia que tem potência para democratizar e transformar as práticas de atenção à saúde, de organização dos serviços e sistemas, e de controle social. A educação permanente pode ser uma estratégia poderosa para produzirmos políticas descentralizadoras, coerentes com os princípios do SUS, e, portanto, deve e pode ser utilizada na formação de profissionais de saúde.

Considerando os pressupostos da educação permanente, os objetivos primordiais deste eixo compreendem:

- O desenvolvimento e a ampliação da capacidade dos estudantes para analisar a conjuntura política na área da saúde;

- A produção de eficácia comunicacional entre as pessoas e as instituições, além do gerenciamento estratégico de conflitos e de situações de crise;

- A ampliação da capacidade de tomada de decisão de forma coletiva e pactuada, garantindo governabilidade e qualidade de gerência ao planejamento em saúde;

- A construção de competência para desenvolver e articular estratégias e ações em saúde que considerem a responsabilização, a viabilidade político-econômica, potencialidades e vulnerabilidades, para imprimir trajetórias descentralizadoras, criativas, transformadoras e acumuladoras de forças e aliados;

- O desenvolvimento de capacidade para estabelecer agenda estratégica no planejamento, implantação, acompanhamento e avaliação dos projetos e das ações em saúde. Nesse sentido, que os profissionais em formação sejam capazes de utilizar indicadores de processo e de resultado, considerando as diferentes perspectivas dos atores envolvidos nos projetos e ações $^{12}$.

\section{Como Chegar Lá}

Esses quatro eixos passaram a compor a base dos projetos pedagógicos dos cursos de Medicina, Enfermagem e Odontologia do Unifeso. A proposta é que passem a estar presentes em todas as atividades realizadas, incluindo as situações-problema, as narrativas da prática, os planos de cuidado e os planos de intervenção.

A partir desta reflexão, surgiram novos desafios ao se lançarem questões para a plenária, como: "quais são os saberes necessários para contemplar as temáticas considerando os eixos de formação?" e "como articular esses saberes?".

Neste ponto, torna-se fundamental refletir sobre como processar a seleção de conteúdos na conformação curricular dos três cursos. Saippa-Oliveira, Koifman e Pinheiro nos ajudam nesta reflexão, quando consideram a formação em saúde como um processo muito mais amplo do que o manejo de técnica, procedimentos e instrumentos. O cotidiano do profissional de saúde não se esgota em sua natureza técnica, mas apresenta dimensões nas quais se expressam valores de ordem moral ou ética, ideológica ou econômica. E, quanto melhor a compreensão da sociedade onde se insere, maior a capacidade profissional de trabalhar em equipe. Assim, tal consideração sobre a dimensão sociocultural dos conteúdos é fundamental:

Sem o devido questionamento sobre a dimensão sociocultural dos conteúdos, ou sobre a aplicação de métodos de ensino-aprendizagem ao longo do processo de formação, corremos o risco de criarmos leituras unilaterais das possibilidades de transformação da educação dos profissionais. Contribuímos de maneira velada e decisiva para legitimação e manutenção de currículos normativos que apresentam baixo potencial de mudança das práticas profissionais em direção à integralidade. A necessidade de superar falsas dicotomias no desenvolvimento das práticas em saúde, como aquelas que se corporificam nas polarizações - ações preventivas/ações curativas, ações individuais/ ações coletivas, cuidado/cura ou clínica/saúde coletiva, por exemplo -, exige um cruzamento de saberes e oportunidades de aprendizagem que envolvem a capacidade de se trabalhar em equipe nos vários pontos da rede. Tomam-se os atributos da política de saúde como expressão da construção da cidadania, consolidando, então, práticas de integralidade no currículo $^{13}$.

Além da seleção de conteúdos, há que se considerar sempre a formação baseada nos quatro pilares da educação: (1) o aprender a conhecer, relacionado ao prazer da descoberta, da curiosidade, de compreender, construir e reconstruir o conhecimento; (2) o aprender a fazer, que, além das questões técnicas, valoriza a competência pessoal que capacita o indivíduo a enfrentar novas situações de trabalho: saber 
trabalhar coletivamente, ter iniciativa e saber resolver conflitos; (3) o aprender a conviver, que significa compreender o outro, ter prazer no esforço comum, participar em projetos de cooperação; (4) o aprender a ser, que diz respeito ao desenvolvimento integral da pessoa: inteligência, sensibilidade, sentido ético e estético, responsabilidade pessoal, espiritualidade, pensamento autônomo e crítico, imaginação, criatividade e iniciativa ${ }^{3}$.

É preciso, ainda, pensar que, ao se compor às bases curriculares, a mudança que se propõe para a formação deve acompanhar uma transformação da atenção à saúde. Por isso, não se pode conceber teoria dissociada da prática e nem prática esvaziada de teoria. É preciso contestar a concepção do currículo normativo que sustenta que, primeiro, o aprendiz domina a teoria, para depois entender a prática e a realidade ${ }^{14}$.

A reflexão de como chegar ao currículo vislumbrado deve ser orientada pela lógica da complexidade, caracterizada pela congregação de elementos que constituem as partes, que, ao se somarem, não formam o todo. Isso porque cada parte apresenta sua especificidade e, em contato com as outras, modificam-se as partes e também o todo. Dessa forma, complexidade é o que não atua a partir de suas ações individuais e isoladas, mas suas ações integradas e dependentes assumem outra forma de expressão e adquirem novas faces ${ }^{15,16}$. É assim que queremos configurar a relação dos saberes e fazeres no currículo a partir dos eixos que nos propomos construir e reconstruir.

\section{CONSIDERAÇÕES FINAIS}

As reflexões geradas na oficina apontaram a necessidade de integração dos currículos para a formação das diversas profissões da saúde. Não há como negar a coerência dessa proposta com a organização do desejado trabalho em equipe. A construção dos quatro eixos em comum (Semiologia Ampliada do Sujeito e da Coletividade; Ética e Humanismo; Construção e Produção do Conhecimento; e Política e Gestão em Saúde) foi um avanço para a integração dos projetos pedagógicos dos cursos de Medicina, Enfermagem e Odontologia do Unifeso. Porém, entendemos que este movimento de concepção teórica encontra fluidez e entraves no cotidiano das práticas pedagógicas dos cursos.

Assim, o envolvimento dos professores, estudantes, profissionais de saúde, gestores de serviços, usuários e outros atores é fundamental para dar sentido prático aos eixos propostos. Esse movimento vem ganhando vida a partir da construção coletiva, que considera as propostas de cada eixo, na formulação de problemas que serão processados no módulo tutorial, na concepção dos planos de cuidado e de intervenção nos diversos cenários de aprendizagem e de atenção à saúde e na construção e consolidação de uma proposta integrada de avaliação.

Enfim, pensar a formação integrada nos três cursos representa a valorização de espaços participativos. Além de constituir motivo de entusiasmo e satisfação e, conseqüentemente, contribuir para fortalecer as inovações, é fundamental que os meios sejam coerentes com o conteúdo das mudanças. Feuerwerker contribui com essa conclusão, apontando a necessidade de contar com espaços democráticos no processo de mudança: comunicação, mecanismos de diálogo e de escuta são críticos para a construção e também para a integração de novos currículos ${ }^{17}$.

Assim, pensamos como força motriz de nosso empenho e trabalho a sempre presente idéia do "currículo que queremos". Por isso, o texto deste relato de experiência se encerra, mas não termina, uma vez que o velho ditado é a máxima no presente: "caminhos se fazem caminhando". O nosso apenas começou. Então, mais desafios estão lançados.

\section{REFERÊNCIAS}

1. Dowding TJ. The application of a spiral curriculum model to technical training curricula. Education Technology 1993; 33(7): 21-30.

2. Garanhani ML. Habilitando o mundo da educação em um currículo integrado de enfermagem: um olhar a luz de Heidegger São Paulo, SP; 2004. Doutorado [Tese] Universidade de São Paulo.

3. Delors J. Educação: um tesouro a descobrir. Relatório para a UNESCO da Comissão Internacional sobre Educação para o Séc. XXI. São Paulo: Cortez; 2004.

4. Ceccim RB. Equipe de saúde: a perspectiva entre-disciplinar na produção dos atos terapêuticos. In: Pinheiro R, Mattos RA. org. Cuidado: as fronteiras da integralidade. Rio de Janeiro: Hucitec/ABRASCO; 2004. p.259-78.

5. Fazenda I. Interdisciplinaridade: qual o sentido? São Paulo: Paulus; 2003.

6. Japiassu H, Marcondes D. Dicionário básico de filosofia. 3.ed. Rio de Janeiro: J. Zahar; 2001.

7. Fundação Educacional Serra dos Órgãos. Centro Universitário Serra dos Órgãos. Projeto PolíticoPedagógico Institucional - PPPI. Teresópolis, RJ: UNIFESO; 2006. 
8. Campos GWS, Amaral MA. A clínica ampliada e compartilhada, a gestão democrática e redes de atenção com referências teórico-operacionais para reforma do hospital. Ciênc. Saúde Colet 2007; 12(4): 849-59.

9. Taylor C. Argumentos filosóficos. São Paulo: Loyola; 2002.

10. Merhy EE. Saúde: a cartografia do trabalho vivo. 2.ed. São Paulo: Hucitec; 2005.

11. Demo P. Formação permanente e tecnologias educacionais. Petrópolis, RJ: Vozes; 2006.

12. Brasil. Ministério da Saúde. Secretaria de Gestão do Trabalho e da Educação em Saúde. Caderno do especializando. Curso de especialização em ativação de processos de mudança na formação superior dos Profissionais da Saúde. Rio de Janeiro: ENSP/FIOCRUZ; 2005.

13. Saippa-Oliveira G, Koifman L, Pinheiro R. Seleção de conteúdos, ensino-aprendizagem e currículo na formação em saúde. In: Pinheiro R, Ceccim RB, Mattos RA. orgs Ensinar saúde: a integralidade e o SUS nos cursos de graduação na área da saúde. Rio de Janeiro: Abrasco; 2006. p. 205-28.

14. Saippa-Oliveira G, Koifman L. Integralidade do currículo de medicina: inovar/transformar, um desafio para o processo de formação. In: Marins JJN, Rego S, Lampert JB, Araújo JGC orgs. Educação médica em transformação: instrumentos para a construção de novas realidades. São Paulo: Hucitec; 2004. p.143-64.

15. Morin E. Os sete saberes necessários à educação do futuro. 8. ed. São Paulo: Cortez; Brasília: Unesco; 2003.

16. Petraglia IC, Morin E. A educação e a complexidade do ser e do saber. 8.ed. Petrópolis, RJ: Vozes; 2006.

17. Feuerwerker LCM. Gestão dos processos de mudança na graduação em medicina. In: Marins JJN, Rego S, Lampert JB, Araújo JGC. orgs. Educação médica em transformação: instrumentos para a construção de novas realidades. São Paulo: Hucitec; 2004. p.17-39.

\section{CONFLITO DE INTERESSE}

Declarou não haver

\section{ENDEREÇO PARA CORRESPONDÊNCIA}

Verônica Santos Albuquerque

Rua Prefeito Sebastião Teixeira, 145 - apto 201 - bloco 01 - Tijuca 25953-300 - Teresópolis - RJ

E-mail: veronicatere@gmail.com 